\title{
A FAVOR DEL DERECHO A LA MEMORIA: CINCO NOTAS PROVISORIAS
}

\author{
Pablo Salvat Bologna \\ Director Magister Ética Social y Desarrollo Humano, \\ Departamento Ciencias Políticas y RRII, \\ Universidad A. Hurtado. \\ Profesor Facultad de Derecho, UDP. \\ psalval@uahurtado.cl
}

\begin{abstract}
"Oi millones de peces que son tumbas con pedazos de cielo adentro, con cientos de palabras que no alcanzaron a decirse, con cientos de flores de carne roja y pedazos de cielo en los ojos. Oi cientos de amores que quedaron fijos en un dia soleado/llovieron carnadas desde el cielo.../fueron arrojados/lueven/asombrosas cosechas de hombres caen para alimento de los peces en el mar/Viviana oye llover tierras santas/ oye su hijo caer como una nube sobre la cruz despejada del Pacifico" (Raúl Zurita)

"El Holocausto se pudo llevar a cabo con la condición de neutralizar el impacto de los impulsos morales primitivos, de aislar la maquinaria de la muerte de la esfera en que esos impulsos nacen y funcionan y de hacer que dichos impulsos pasen a ser marginales o irrelevantes para la tarea"

(Zigmunt Bauman)

"El plano ético precede al plano de la ontología" (E. Lévinas)
\end{abstract}

\begin{abstract}
RESUMEN
En este artículo exponemos algunos elementos relacionados con la hipótesis siguiente: en el proceso de reconstrucción de una cultura pública democrática en el pais requerimos incorporar el pasado de violaciones a derechos humanos, en este caso, como ejercicio colectivo del derecho a la memoria. La justificación de esto tiene que ver con un presupuesto: no podremos construir un presente-futuro como sociedad decente sobre la base de negar el pasado, o de banalizarlo como un mero epifenómeno. Los olvidos interesados contribuyen a su manera a imposibilitar una ética civil compartible en el espacio público, y por tanto, terminan de un modo u otro, afectando la densidad de la vida democrática. Ello se revela de la mayor importancia en tiempos de una globalización atravesada por una dialéctica de modernidad/modernización que tiende a disolver las claves del reconocimiento mutuo y las posibilidades de una sociedad justa, a nivel nacional o mundial.
\end{abstract}


Palabras Clave: derecho a la memoria, derechos humanos, cultura política pública, moralidad, ética civica, democracia.

\begin{abstract}
This article aims to expose some items related to the following hypothesis: The reconstruction of democratic public culture of this country needs to recover its past time of human rights violations as common and collective exereise of the right to remember. This is justified by the following presupposition: It is impossible to build up a present or future decent society by denying or trivializing the past as if it were only epiphenomenical. Prompted oblivions help to make unfeasible civil ethics, shared at public scenario; therefore they contribute to undermine the density of democratic way of life. All this is nowadays highly relevant: globalization with its dialectics modernity / modernization is prone to solve the codes of reciprocal recognition and the possibilities of righteous societies at national or worldly level.
\end{abstract}

KEY WorDs: Right to memory, human rights, public political culture, morality, civil ethics, democracy.

(1) Si uno mira en general la sociedad chilena y el pretendido nuevo orden mundial que se ha ido gestando, y en el cual aquella está inmersa, podemos decir que entramos al nuevo siglo con una pesada herencia para los esfuerzo humanizadores y democráticos. Una herencia marcada por el signo de los distintos Holocaustos que hemos presenciado; desde violaciones a los derechos humanos, mala calidad de vida, nuevas formas de violencia, crecientes brechas en desigualdades en el uso y goce de las libertades, etc. Vivimos un tiempo transicional que afecta no solo los modos de la economía y la política, sino también, los modos culturales, en particular, los referidos a los fundamentos posibles de una ética civil pública, es decir, a los fundamentos del lazo social en la polis nacional y global. Es sabido que el fundamento más aceptable hoy para la convivencia es la propia democracia, pero ella, al mismo tiempo, está amenazada en sus propias significaciones, tanto por el aumento de complejidad que introduce en la sociedad la tecnociencia, como por la opacidad que adquieren las relaciones sociales, lo cual amenaza convertirla en una democracia de espectadores. Por ello, repensar las formas y patrones normativos del vivir juntos implica repensar también la democracia realmente existente y la que desearíamos lograr.

Pareciera que la humanidad y los poderes no pudieran tomar conciencia ética de sus propias limitaciones y daños sino-como lo expresaba Hans Jonas-, mediante una heuristica del temor, esto es, por intermedio del miedo y la responsabilidad por las consecuencias de los usos y abusos del poder. En la actualidad uno se pregunta cómo reorientar las miradas y conductas, personales e institucionales, en medio del nuevo contexto; en medio de la frágil memoria del futuro que llevamos a cuestas, acorde a qué patrones valórico-normativos, si los mapas morales habituales parecen sucumbir ante la rapidez de los cambios tecnológicos, la manipulación mediática, la expansión ilimitada de criterios mercantiles, $\mathrm{o}$ ante una lógica de poder por el poder. Al parecer, la profecía de un "ser para la muerte" como destino y proyecto ha encontrado entre nosotros 
hace ya más de treinta años, y también hoy en el concepto de guerra preventiva o de partición del mundo en una ya conocido y recreado eje del bien y del mal, una alucinante y dolorosa actualidad. $Y$, sin embargo, paradojalmente, muchas de esas acciones se ejecutan bajo la bandera y salvaguardia de los mismos "droits de l'homme".

A esta situación se llega quizá -sigo a $\mathrm{H}$. Arendt-, porque desde que empezamos a vivir en un solo mundo, en una Humanidad con mayúsculas que se autoorganiza por doquier; la pérdida del hogar o del estatus de ciudadano y nacional se identifica a veces -históricamente-, con la expulsión de esa misma humanidad. Una vez que se produce una situación de este tipo, entonces se pondrá a la orden del día resguardar un cierto derecho a la memoria (personal y colectivo), así como uno a la condición de humano, tan fragilizada queda su figura en sus relaciones con los distintos poderes después de los diversos Holocaustos sufridos en el norte como en el sur del hemisferio, en pleno auge y despliegue de la epopeya moderna. Al decir de Habermas, por ejemplo, esta situación de falta de autoconciencia del lado oscuro que genera el mismo progreso ilustrado tiene mucho que ver con la incapacidad occidental de hacer suya también la razón anamnética. Esa culpable incapacidad se muestra en una pretensión universalista que se mueve en los sillares de una pérdida de la memoria, y de un acrecentado desencantamiento del mundo. Y ello revierte sobre el drama mismo que acompaña esa historia: como expresión de insensibilidad para con quien sufre, es excluido o marginado; a su vez, como oídos sordos para la reclamación de una justicia universal'.

(2) Es en el marco entonces de esta dialéctica de modernidad-modernización en clave globalizante -que tiende a disolver las claves mismas del reconocimiento mutuo que funda certidumbres compartibles al interior de las diversas comunidades políticas-, que se replantea en general el tema de la memoria histórica con sus distintas aristas y lecturas. En qué medida y qué debemos recordar u olvidar, no solo como individuos, sino también como comunidades politicas. Qué rasgos de nuestra convivencia histórico-politica deben pasar el tamiz del mero olvido, interesado para conformar una nueva tradición o un nuevo elemento del ethos cívico? Estas cuestiones se han puesto de relieve en lo que a nosotros concierne e interesa de manera dramática a partir del Golpe de Estado de 1973 y dejan una estela de problematicidad hasta nuestros días, incidiendo en la propia marcha de la reconstrucción democrática en curso.

También entre nosotros -y por supuesto no solo en Chile-, hemos experimentado históricamente esa figura paradójica de una modernidad modernizante en claro-oscuro: iluminando nuevos territorios de la subjetividad, ciertos derechos y posibilidades autonomizadoras en muchas direcciones y, al mismo tiempo, dando curso a los peores desmanes y sumisiones de lo humano, a nuestra propia "monstruosidad". Estas paradojas -reales, dolorosas-, su ubican al centro mismo de la búsqueda constante de más progreso y más modernidad de los distintos proyectos sociopoliticos, y no en sus márgenes, como a veces se ha pretendido sostener. Entre sus consecuencias,

1 Cfr. J. Habermas, Frogmentos filosófico-teológicos, Trotta, Madrid, 1999. En especial, véase alli el texto "Israel o Atenas: a quién pertenece la razón anamnéstica?", pp. 99 y ss. 
aquella relacionada con la producción sistemática de una distancia respecto al otro concreto, que termina pasando a llevar la sustancia propia de la moralidad, entendida -siguiendo a Bauman- como responsabilidad incondicional, como "un deber hacia el otro (no una obligación), un deber que precede a todo interés". Entre las transformaciones generadas por el devenir moderno ha estado la producción de la separación social. Esa separación "hizo posible que miles de personas asesinaran y que millones observaran el asesinato sin protestar. El logro tecnológico y burocrático de la sociedad racional y moderna fue el que hizo posible esa separación “2.

Si entiendo bien a Barman, señala que hay una conexión más estrecha de la que se ha supuesto entre el proceso moderno y el Holocausto. $\mathrm{O}$, dicho de otra forma, que este último no es un mero epifenómeno, algo externo a ese mismo proceso. En gran medida, Auschwitz ha pasado a la historia como un problema meramente "judío" o "alemán", impidiendo que "pueda convertirse en un problema universal de la moderna condición humana, $y$, por tanto, en una propiedad pública"'. Lo cual -de pasada-, justifica la pertinencia del ejercicio público de una interrogación crítica respecto a nuestra propia manera de ensalzar progresos y reformas modernizadoras como vía regia hacia una vida mejor. Pero lo que nos interesa de manera particular es su argumentación -que sigue a Lévinas-, respecto a la importancia de la moralidad como expresión de relaciones intersubjetivas primordiales, previas incluso al proceso de socialización que sufren los sujetos. La moralidad sería algo que la sociedad puede maniobrar, reforzar, o simplemente bloquear, pero no crear desde la nada. De allí que una conducta inmoral, es decir, una que no se hace responsable por el otro, no sea meramente imputable al contexto societal o político ${ }^{4}$.

Asumir el pasado de violaciones a derechos humanos en Chile señala también las conexiones que se han dado entre proceso de modernizaciones y moralidad, y pediría interrogarse hasta qué punto el modelo de modernizaciones aplicado acá refuerza o más bien bloquea la expresión de lo moral, entendido aquí como responsabilidad incondicional por el otro. Todo lo cual apunta en una dirección reflexiva que nos interesa subrayar de manera particular: un asentamiento y profundización del tránsito a la democracia no pasaría solamente por afirmar sus aspectos legalformales, o económicos, sino también, por la recreación de una cultura política pública ad hoc. Una en la cual los impulsos morales se vean acogidos y no preteridos. Una en la cual pueda interrogarse la "administración social de la intersubjetividad" que se realiza en el espacio público.

Es en función de esa reconstrucción de nuestra cultura política pública que tendríamos que discutir la importancia de una suerte de derecho a la memoria. Darle un espacio en una cultura

2 Véase de Z. Bauman, (1997) Modernidad y Holocausto, Ediciones Sequitur, Madrid, p. 250.

3 Ibid., Z. Bauman, p. 287. Algo que a su manera ya habia visualizado La Dialéctica de la llustración (Horkheimer/Adorno).

4 El mismo Lévinas tiene también el diagnóstico de que la evolución del pensar occidental y la tragedia de Auschwitz se ha dado o ha sido posible -entre otras razones-, desde el predominio de la tradición greco-idealista, dejando fuera de su jurisdicción lo que Metz (comentado por Habermas, cfr. Nota 1) manifiesta como "el olvido del espíritu de Israel". En esta misma dirección puede verse de J. B. Metz "Cristianos y judios después de Auschwitz", en Más allá de la religión burguesa, Sígueme, Salamanca, 82, pp. 25 y ss. 
politica pública al cultivo de la memoria implica cultivar o traer al presente-futuro la proximidad del otro herido y pasado a llevar de las víctimas; es asumir las responsabilidades sin evadirlas en un generalizado grito de "fuente ovejuna" o de diluirlas en un larvado contextualismo justificador y a su vez, desde allí, interrogar la "administración social de la intersubjetividad" que el orden político modernizador produce. Qué debemos recordar y qué debemos olvidar, el mismo planteamiento de un derecho a la memoria (entendida como memoria histórica con especial énfasis en las víctimas), se vuelve un objeto de debate en el espacio ético-político ${ }^{5}$. Entre otras cosas, porque hay poderosos sectores identificados con el proceso modernizador manu militari que no están dispuestos a acordar una mirada normativa común en tomo a una idea de sociedad justa o de una sociedad decente desde la cual evaluar como inadmisible (moralmente hablando) los sucesos del mismo Golpe de Estado y lo que vino después. Dicho de otra forma, no hemos podido elaborar una comunidad de valores que nos permita hacernos cargo de manera mancomunada del pasado doloroso, no solo para lamentarlo, sino también para asumirló.

(3) La importancia del ejercicio de un derecho a la memoria proviene de un presupuesto: no nos será factible construir un presente y un futuro decente como sociedad, es decir, de una sociedad que no humille a sus miembros, sobre la base de negar el pasado como si no hubiera existido. De la misma manera que nuestra identidad personal está de algún modo articulada a los recuerdos y la memoria, y no es pensable sin ellos (al menos no si aquellos fallan de manera completa), del mismo modo la vida en común como sociedad se sostiene también en algún tipo de memoria histórica y colectiva, y lo que pueda o no olvidarse pasa a ser decisivo en las posibilidades de constituir una comunidad política propiamente tal, es decir, una en la cual -parafraseando a $\mathrm{H}$. Arendt-, las palabras y los actos no estén divorciados entre sí; una en la cual los actos no se orienten a violar o destruir, sino a establecer relaciones y crear nuevas realidades ${ }^{7}$. Hablamos aquí de memoria histórica y memoria colectiva en el sentido dado a ésta por Halbwachs, que la entiende como la "capacidad de ordenar el sentido del pasado en función de las representaciones, visiones del mundo, símbolos o "nociones" que permiten a los grupos sociales pensar el presente" ${ }^{n}$. Es decir, puesta en un enmarque normativo. Visto desde este punto

5 El tema de la memoria ha tenido un importante espacio en las reflexiones históricas, sociológicas y culturales ligado a los elementos expuestos en la nota (1) y ha producido una ingente bibliografia que no podemos recoger aqui. Puede verse entre otros, M. Halbwachs, Les cadres sociaux de la mémoire. Paris: Alban Michel, 94; del mismo autor, La mémoire collective, Paris: Alban Michel, 97, con un enfoque desde una sociología de la memoria. Tambien, T. Todorov, Los abusos de la memoria, Barcelona: Paidos, 2000; P. Ricoeur, La mémoire, l'histoire et l'oubli, Paris: Editions du Seuil, 2000; J. L. E. Jelin, Los trabajos de la memoria, BsAs: Siglo XXI, 2002; por cierto, no estamos hablando de la memoria como expresión de un acto subjetivo, como memoria hábito, sino de memoria-recuerdo. Esa distinción la establece ya Bergson, y será después retomada por P. Ricoeur.

- Véase de Yosef H. Yerushalmi "Reflexiones sobre el Olvido", en Usos del Olvido (1989), Nueva Visión, BsAs, pp. 22 y ss.

Cfr. H. Arendt, La condición humana, Paidós, Barcelona, 98.

* Marie-Claire Lavabre, "Maurice Halbwachs y la sociologia de la memoria", en A. Perotin-Dumon (dir), Historizar el pasado vivo en América Latina, http///etica.uahurtado.cl/historizarelpasadovivo/es. contenido. php, p. 8. 
de vista es que el derecho a la memoria nos parece ingrediente primordial para una nueva ética cívica.

El tema de la violación a derechos humanos, sus consecuencias y la forma en que debemos tratarlo desde el punto de vista de su recuerdo-presente, no ha dejado de estar en un plano importante de la información pública. Desde el Informe Rettig (Comisión de Verdad y Reconciliación), la detención de Pinochet en Londres, la Mesa de Diálogo, el Informe Valech sobre Prisión Política y Tortura, hasta hoy, a través de los distintos juicios que se siguen a eventuales responsables en esas violaciones. Con todo, no se trata aquí de una línea más o menos continua y articulada entre sí para ese tratamiento. En varias oportunidades se han intentado iniciativas para dar por cerrado el debate y los procesos en curso. Sin embargo, cada vez, algún hecho imprevisto lo vuelve a reponer en escena. El hábito de barrer bajo la alfombra lo que nos incomoda no ha dado resultados. Las cuestiones relativas a un derecho a la memoria tienen -entre otras cosas- que hacerse cargo de una pregunta esencial: cómo educar y auto-educarnos en cuanto sociedad, después de Valle Grimaldi, Tres y Cuatro Álamos, Londres 38, detenidos-desaparecidos y otras expresiones devastadoras del daño al otro? Este nos parece el punto crucial. Y sin embargo, no hay acuerdo en la propia sociedad. Pareciera que fuere necesario dar incluso justificaciones de su pertinencia. Pues, como nos señala Adorno “(...) el que se haya tomado tan escasa conciencia de esa exigencia, así como de los interrogantes que plantea, muestra que lo monstruoso no ha penetrado lo bastante en los hombres (...)". Lo cual, a su vez, no deja de ser indicativo de que -mutatis mutandi- lo sucedido podría volver a suceder, "síntoma-dice el mismo Adorno-, de que la posibilidad de repetición persiste en lo que atañe (...) al estado de consciencia e inconsciencia" de los humanos respecto a esos sucesos y sus implicancias?

Distinguir, en una tarea interpretativa motivos de avance y retroceso respecto al pasado-presente, demanda poner en juego alguna medida normativa que pueda señalar un rumbo evaluativo para los actos y sucesos históricos. $\mathrm{El}$ interés de trasfondo que orienta lo que vamos diciendo tiene que ver con la necesidad de contribuir a nuestra propia liberación y autoliberación como sujetos y como sociedad; una liberación que no se hace posible de cualquier manera, sino desde el ejercicio compartido y público del conocimiento y recuerdo de lo sucedido en torno a su causas, responsabilidades, consecuencias. Caminos preferentes serán entonces la obtención de verdad, justicia, reconocimiento y reparación, puestos como pasos indispensables a cualquier pretensión de reconciliación que represente más que una mera teatralización.

En palabras de Metz: "Tener conciencia histórica y tratar de vivir de ella significa precisamente no eludir las catástrofes, al igual que significa, en cualquier caso, jamás negar una autoridad o hacerla despreciable: la autoridad de los que sufren"10. Es lo que de algún modo se ha dado gracias al Informe sobre Prisión Política y Tortura, conocido también como Informe Valech (2004), donde los afectados pudieron, vía la mediación del relato, reencontrarse en algo

9 Véase, T. Adorno, "La educación después de Auschwitz", en Consignas, Amorrortu, Bs. As 93, p. 80.

10 J. B. Metz, Más allá de la religión burguesa, op. cit., p. 26. 
con la sociedad; sentirse acogidos, escuchados; percibir que el paso por el infierno humano y terreno - a manos de compatriotas-, no fue un mero invento, una alucinación o una mera equivocación -como, por otra parte, se quiso hacer creer. $\mathrm{Y}$, sin embargo, a pesar de todo el trabajo realizado al respecto desde distintos ángulos y realces, lo vivido en esos largos años no ha podido aún transformarse -como debiera-, en una interrogación reflexiva, en debates públicos, investigaciones diversas, rememoraciones, que apunten a develar las estructuras de nuestros hábitos sociales, de nuestra cultura civil, y el lugar que en ellas ocupan el autoritarismo y las tendencias a la impunidad social y la violencia interpersonal. La tragedia vivida en esos años pone un signo de interrogación para todos nosotros, en función de examinar qué formas de vida y qué instituciones hemos forjado que han permitido lo que sucedión ${ }^{n}$.

(4) Por qué el tema de los derechos humanos, de sus consecuencias, de cómo tratar la memoria de lo sucedido, se resiste al modelo más o menos típico que la sociedad chilena -por supuesto sus elites-, frecuentó cada vez que enfrentó una crisis de envergadura en su historia -léase amnistía, olvido, perdón o impunidad-, haciendo de las exigencias de verdad, justicia, reparación, memoria, exigencias no renunciables?

Entre otras cosas, quizá porque el quiebre del 73 nos ha permitido redescubrir el sentido y eventual significado de esos mismos derechos humanos y su implicancia (digamos, para una cultura política basada las más de las veces en la negación del otro). Esos derechos que, hasta entonces creíamos formaban parte del patrimonio de ideas y prácticas presentes en la tradición republicana chilena, cuya matriz se pretendia más o menos liberal y plural. Post once de septiembre se abre la oportunidad de reinterrogar y resignificar la trayectoria de la tradición histórica y política nacional; reinterrogarla no solo en su superficie, sino también en los supuestos valóricos, normativos, éticos desde los que se ha construido y funcionado en tanto cultura política pública en las formas y gramáticas de su sociabilidad.

La situación del 73 en adelante nos permite redescubrir el valor de la vida, la persona, la palabra dada incluso en medio del conflicto y la diferencia, situación que ningún quiebre anterior de la historia nacional puso tan en claro, poniendo sobre la mesa la necesidad de considerar y hacer conciencia de lo que Arendt llamó - para situaciones limites- una suerte de derecho a la condición humana, con igual importancia que el derecho a la libertad. Es probable que ello se deba a que esas violaciones no fueron algo acotado, casual y ocasional, sino una acción sistemática y sostenida en el tiempo, de una envergadura tal, que se ha instalado en nuestra historia como la

1 Recomendamos leer el testimonio de una mujer, Luz de las Nieves Ayress Moreno, que supo más de algo del infierno en el trato recibido sin ninguna acusación ni juicio correspondiente entre 1973 y 1976. Bastaría ese solo testimonio para poner en duda nuestra autoimagen de país de triunfadores y modernistas. También puede verse el capitulo 8 del Informe Valech, dedicado a las consecuencias de la prisión política y la tortura. Si ser "exitosos" conlleva esa brutalidad y degradación del otro anatematizado convenientemente, entonces, el progreso de las modemizaciones lleva en su frente inserito el sello de la más grande indiferencia moral. 
herida ética más profunda para la convivencia como nación, y por tanto, imposible de eludir en sus implicancias para nuestra cultura política pública.

¿Qué ha pasado con nuestra manera de abordar estas cuestiones? ¿Cuál es el trasfondo de la acción y dirección que se ha seguido desde el punto de vista de nuestra sociabilidad -ethos-, y que influye hasta nuestros dias el abordaje de estos temas? La adhesión cultural al autoritarismo y los prejuicios como forma de relación social y política, -que puede tener distintos signos políticos- no ha sido un hecho casual. Su recepción en la acción y mente de muchos chilenos tampoco. Puede uno preguntarse acorde a qué patrones valórico-normativos podemos evaluar la memoria de lo sucedido, si los mapas morales habituales se revelan colonizados por una moralidad privado-pública de lo "desechable" o una meramente cínica, es decir, una en la cual los sujetos, y a veces también las instituciones, pierden su capacidad de asombro y borran su conciencia moral en pos de una vida en la impunidad, o de esa nueva y extraña figura emergente de "ceguera histórica insuperable" respecto a las responsabilidades y consecuencias de sus actos pasados .

(5) No podemos aqui decir algo conclusivo al respecto. Pero sospechamos que la historia social, politica, y cultural de Chile tanto la del pasado cercano, como la del pasado anterior, manifiesta distintos signos permanentes de negación y exclusión del otro, de su dignidad, palabra y derechos, sea en el ámbito material o simbólico. Podemos leer el proceso histórico de nuestra propia búsqueda de modernidad como uno atravesado transversalmente por un rasgo reiterado y pocas veces relevado: la presencia de una larga y no terminada disputa por el reconocimiento expresable en distintos planos de la existencia social. Con esto queremos indicar que el proceso de modernización desde antes de 1973, esto es, el permanente esfuerzo del país y sus elites dirigentes por ser modernos -y hacernos modemos en distintas claves, en suma-, desde que nos constituimos en nación independiente, refleja con distinta agudeza esa disputa -sea el año 1891, en 1931 o más cerca de nosotros.

Destaca en nuestra historia una suerte de gramática moral predominante que se ha mostrado incapaz para procesar deliberativamente, inclusivamente, razonablemente, el conflicto de intereses, fines y valores, la diferencia, la aspiración a ser sujeto de derechos, del que no es igual a mi, en capital social, cultural o económico; como si el devenir de nuestra cultura política pública expresara una resistencia a cumplir con la aspiración a vivir como iguales, y a desentrañar qué quiere decir esto desde el punto de vista de las actitudes, instituciones, políticas que se elaboran y deciden. Como si lo que provoca distancia o dificultad de ser asumido no pudiera nombrarse.

El problema en la lucha por el reconocimiento -esto es, en las búsquedas del no-sujeto por acceder a la categoria de sujeto-, que se manifiesta en la historia nacional es que ella, miremos los hechos, cuesta sangre; tiene un "costo social" que sale caro en términos de dignidad y honor. Esa lucha tiene costos humanos elevados porque nadie está dispuesto a pagar así como así el precio del reconocimiento del otro. Unos se ven a sí mismos como poderosos, o como aquellos a los cuales puede articularse la configuración del país como tal; los otros se debaten porque en esa asimetría de facto quieren al menos ser vistos y considerados como sujetos de derecho. Pero, los primeros no quieren reconocer ese derecho (a ser sujeto de derechos), mientras estos últimos no se rindan ante ellos, es decir, no les reconozcan sus méritos "innatos" -o por tradición y expertise-, 
a conducir los destinos de la nación. Y sin embargo, su tratamiento histórico está marcado por la ambigüedad, cuando no por la omisión y el olvido. Las fracturas de esas confrontaciones no terminan de fraguar y ser aquilatadas en las pacificaciones implicitas que traen las amnistías, las reconciliaciones desde arriba, o los llamados a un perdón generalizado. Pero ¿son conducentes esas actitudes para el logro de la pacificación buscada? ¿Acaso esa manera de vérsela con los conflictos, con el daño al otro, con el sufrimiento, no terminan instaurando o pretendiéndolo, una impunidad generalizada? El temor al fragor del conflicto, a su reapertura, a revivir situaciones dolorosas pareciera aconsejar esa postura de fuga hacia adelante. Pero con esa fuga, con los llamados a una reconciliación que no pasa por la verdad y la justicia, lo que estamos haciendo es perpetuar las asimetrías y los dolores, postergar el reconocimiento y sus condiciones, seguir sin saber procesar los conflictos, sin por tanto, poder vivir en una democracia plenamente tal. Con el acicate a la impunidad y a la falta de ejercicio de una memoria histórica como conducta cultural y política, seguimos sin reconocer para todos la universal reinvindicación del derecho a ser sujetos de derecho. Hacia el pasado y el futuro.

Pero no solo eso. Las amnistías, los olvidos o desmemorias interesadas contribuyen también -a su manera-, a la imposibilidad de que exista entre nosotros una más sólida ética civil compartible. Una que lleve los rasgos del reconocimiento social, la justicia y promueva una cultura del responder por nuestros actos frente al otro. La tendencia es más bien a diluirla -esa ética cívica que necesitamos-, en los contextos. Mirado positivamente entonces, un derecho a la memoria conlleva una posibilidad abierta de reencuentro con la historia. Se puede confiar en la historia, obtener de ella ciertas lecciones y normas para la acción -presente y futura-, si no negamos las catástrofes, si no edulcoramos el daño al otro. Tenemos el deber de reconstruir y cultivar una memoria histórica y colectiva para no caer, como dice X. Exteberria, en "olvidos de pérdida" relativos a los demás, es decir, para no generar condiciones que harian desaparecer de nuestra memoria lo que se precisa para la verdad, la justicia, el reconocimiento, la dignificación de las víctimas $^{12}$.

Nada hay en el presente, claro está, que pueda garantizar a priori la no repetición a futuro de violaciones a derechos humanos como las que quedan consignadas en las distintas comisiones históricas de la verdad. Pero, contrario sensu, parece que su desconocimiento, su subsunción en un olvido cómplice no ayudarían mucho más a cumplir con ese objetivo. Parece llevar razón H. Arendt cuando nos dice que "sin la acción para hacer entrar en el juego del mundo el nuevo comienzo de que es capaz todo hombre por el hecho de nacer, no hay nada nuevo bajo el sol; sin el discurso para materializar y conmemorar, aunque sea de manera tentativa lo "nuevo" que aparece y resplandece, no hay memoria; sin la presencia del artificio humano (el mundo), no puede haber memoria de lo que sucederá en los que serán después. Y sin poder, el espacio de aparición que se crea mediante la acción y el discurso en público se desvanece tan rápidamente como los actos y las palabras vivas"13. Por ello entonces una renovación de nuestra cultura

12 Cfr. X. Exteberria, Memoria y Victimas: una perspectiva ético-filosófica, en F, Gómez Isa (cir), El derecho a la memoria, IDDHH P. Arrupe, Universidad Deusto, Bilbao, 2006, pp. 223 y ss.

13 Cfr. H. Arendt, La condición humana, p. 227. 
política pública, de su ethos democrático, demanda un debate abierto sobre el lugar que debe ocupar en ella el ejercicio de un derecho a la memoria. Al menos, para indagar hacia dónde se dirige la "administración social de la intersubjetividad" en el actual modelo de sociedad.

\section{BIBLIOGRAFIA}

\section{BAUMAN, Z.}

Ética posmoderna

Siglo XXI, Bs As, 2004.

BAUMAN, Z .

Modernidad Liquida

FCE, México/BsAs, 2000.

BENJAMIN, W.

Para una crítica de la violencia y otros ensayos

Iluminaciones IV, Taurus, Madrid, 1998.

CRUZ, M. (99)

Hacerse cargo

Barcelona, Paidos, 1999.

HABERMAS, J.

Fragmentos filosófico-teológicos

Madrid, Trotta, 1999.

\section{HABERMAS, $\mathbf{J}$.}

La constelación posnacional

Paidos, Barcelona, Buenos Aires, 2000.

\section{HABERMAS, $\mathrm{J}$.}

El discurso filosófico de la modernidad

Taurus, Madrid, 1987.

FIGUEROA M. /D. MICHELINI (editores)

Filosofia y Solidaridad

Santiago, Universidad Alberto Hurtado, 2007.

\section{LÉVINAS E.}

\section{Ethique et Infini}

Dialogues avec P. Nemo. Paris, Fayard, 1984. 
LIRA, E./B. LOVEMAN/T. MIFSUD, sj/P. SALVAT

Historia, política y ética de la Verdad en Chile: 1891-2001

Santiago, LOM-U.A. Hurtado, 2001.

LOEVMAN B. /E. LIRA

Las ardientes cenizas del olvido: vía chilena de reconciliación política, 1932-1994

Santiago, LOM-DIBAM, 2000. 